\title{
Kompres Air Hangat pada Daerah Aksila dan Dahi Terhadap Penurunan Suhu Tubuh pada Pasien Demam di PKU Muhammadiyah Kutoarjo
}

\author{
Eny Inda $\mathrm{Ayu}^{1}$, Winda Irwanti ${ }^{2}$, Mulyanti ${ }^{3}$ \\ 1,2,3 Sekolah Tinggi Ilmu Kesehatan Alma Ata Yogyakarta \\ Jalan Ringroad Barat Daya No 1 Tamantirto, Kasihan, Bantul, Yogyakarta
}

\begin{abstract}
Abstrak
Demam adalah keadaan tubuh mengalami kenaikan suhu hingga $38^{\circ} \mathrm{C}$ atau lebih. Ada juga yang mengambil batasan lebih dari $37,8^{\circ} \mathrm{C}$, sedangkan bila suhu tubuh lebih dari $40^{\circ} \mathrm{C}$ disebut demam tinggi/hiperpireksia. Demam dapat membahayakan apabila timbul dalam suhu yang tinggi. Demam atau suhu tubuh yang tinggi dapat diturunkan dengan berbagai cara. Kompres air hangat merupakan metode untuk menurunkan suhu tubuh. Kenyataan yang ditemukan di tempat penelitian yaitu di KRIPMD PKU Muhammadiyah Kutoarjo pelaksanaan kompres sebagai salah satu tindakan mandiri untuk menangani demam masih sering diabaikan oleh pasien dan keluarga. Tujuan penelitian ini adalah untuk diketahuinya perbedaan efektivitas pemberian kompres air hangat di aksila dan dahi terhadap penurunan suhu tubuh pada pasien demam di KRIPMD PKU Muhammadiyah Kutoarjo. Desain penelitian menggunakan true eksperimen: two-group pre-post test design. Jumlah populasi sebesar 40 dengan subyek sebanyak 38 orang dengan teknik consecutive sampling. Pengukuran suhu dilakukan sebelum dan sesudah perlakuan menggunakan thermometer air raksa. Analisis data menggunakan uji t. Hasil: Rerata derajat penurunan suhu tubuh sebelum dan sesudah dilakukan kompres air hangat pada daerah aksila sebesar $0,247^{\circ} \mathrm{C}$. Rerata derajat penurunan suhu tubuh sebelum dan sesudah dilakukan kompres air hangat pada daerah sebesar $0,111^{\circ} \mathrm{C}$. Analisis uji t menunjukkan teknik pemberian kompres hangat pada daerah aksila lebih efektif terhadap penurunan suhu tubuh dibandingkan dengan teknik pemberian kompres hangat pada dahi (t hitung=5,879 p=0,000). Simpulan: Teknik pemberian kompres air hangat pada daerah aksila lebih efektif terhadap penurunan suhu tubuh.
\end{abstract}

Kata Kunci: daerah aksila, daerah dahi, kompres air hangat

\section{Warm Compresses Axilla and Forehead in Lowering Body Temperature among Patients with Fever at PKU Muhammadiyah Kutoarjo}

\begin{abstract}
Fever is a condition when body temperature $38^{\circ} \mathrm{C}$ and more. There are also restrictions that took more than $37.8^{\circ} \mathrm{C}$, whereas when the body temperature of over $40^{\circ} \mathrm{C}$ is called a high fever/hyperpyrexia. Fever may be harmfull if you develop a high temperature. Fever or high body temperature can be derived in various ways. Warm compresses a method to lower the body temperature. Found in the fact that research in KRIPMD PKU Muhammadiyah Kutoarjo implementation compress as one independent action to deal with the fever is still often overlooked by patients and families. The purpose of this research was to know the differences between forehead and armpit compress in lowering body temperature among patients with fever at KRIPMD PKU Muhammadiyah Kutoarjo. The Methode of this study used true experimental designs: a two-group pre-post test design. The total population of patient were 40 respondents. The sampling technique was done by consecutive which consisted of 38 respondents. Temperature was measured by thermometer. Data analysis used the $t$ test. $T$ test analysis showed techniques giving a warm compress on the area of the axilla more effective to reduce body temperature than technique of giving a warm compress on the forehead ( $t=5.879, p=0.000)$. In conclusion, The technique giving a warm compress on the area of the axilla is more effective to lowering body temperature.
\end{abstract}

Keywords: warm compresses, the axillary, forehead area

Info Artikel:

Artikel dikirim pada 9 Januari 2015

Artikel diterima pada 9 Januari 2015 


\section{PENDAHULUAN}

Suhu tubuh yang meningkat lebih dari normal atau demam merupakan suatu pertanda adanya gangguan kesehatan dan disebut sebagai keluhan yang dirasakan oleh seseorang tetapi bukan merupakan suatu diagnosis. Suhu tubuh pada kondisi demam dapat digunakan sebagai salah satu ukuran mengenai membaik atau memburuknya kondisi pasien. Demam mengacu pada peningkatan suhu tubuh sebagai akibat dari infeksi atau peradangan sebagai respon terhadap invasi mikroba, sel-sel darah putih tertentu mengeluarkan suatu zat kimia yang dikenal sebagai pirogen endogen yang memiliki banyak efek untuk melawan infeksi(1).

Demam adalah keadaan dimana terjadi kenaikan suhu hingga $38^{\circ} \mathrm{C}$ atau lebih. Ada juga yang mengambil batasan lebih dari $37,8^{\circ} \mathrm{C}$, sedangkan bila suhu tubuh lebih dari $40^{\circ} \mathrm{C}$ disebut demam tinggi/ hiperpireksia. Demam dapat membahayakan apabila timbul dalam suhu yang tinggi. Demam tinggi adalah demam yang mencapai $41,1^{\circ} \mathrm{C}\left(106^{\circ} \mathrm{F}\right)$ atau lebih. Pada demam tinggi dapat terjadi alkalosis respiratorik, asidosis metabolik, kerusakan hati, kelainan EKG, dan berkurangnya aliran darah otak. Selain itu dampak yang dapat ditimbulkan jika demam tidak ditangani maka akan dapat menyebabkan kerusakan otak, hiperpireksia yang akan menyebabkan syok, epilepsy, retardasi mental atau ketidakmampuan belajar(2).

Demam atau suhu tubuh yang tinggi dapat diturunkan dengan berbagai cara. Cara yang paling sering digunakan adalah meminum obat penurun demam seperti Paracetamol ataupun Ibuprofen. Selain itu adalah dengan mengobati penyebab demam, dan apabila ternyata demamnya karena infeksi oleh bakteri maka diberikan antibiotik untuk membunuh bakteri. Tetapi obat- obatan saja tidak cukup, sehingga perlu dilakukan kompres untuk membantu menurunkan suhu tubuh saat demam(3).

Kompres hangat merupakan metode untuk menurunkan suhu tubuh(4). Pemberian kompres hangat pada daerah aksila (ketiak) lebih efektif karena pada daerah tersebut banyak terdapat pembuluh darah besar dan banyak terdapat kelenjar keringat apokrin yang mempunyai banyak vaskuler sehingga akan memperluas daerah yang mengalami vasodilatasi yang akan memungkinkan percepatan perpindahan panas dari dalam tubuh ke kulit hingga delapan kali lipat lebih banyak(5). Lingkungan luar yang hangat akan membuat tubuh menginterpretasikan bahwa suhu di luar cukup panas sehingga akan menurunkan kontrol pengatur suhu di otak supaya tidak meningkatkan pengatur suhu tubuh lagi, juga akan membuat pori-pori kulit terbuka sehingga mempermudah pengeluaran panas dari tubuh(6). Kenyataan yang ditemukan di lokasi penelitian yaitu di Klinik Rawat Inap Pelayanan Medik Dasar (KRIPMD) PKU Muhammadiyah Kutoarjo, dengan jumlah ratarata 40 pasien demam setiap bulan dengan lama 3-4 hari perawatan, pelaksanaan kompres sebagai salah satu tindakan mandiri untuk menangani demam masih sering diabaikan oleh pasien dan keluarga. Selama ini pasien dan keluarga lebih memilih untuk melakukan kompres pada daerah dahi dengan alasan kompres pada daerah dahi lebih mudah dilakukan dan tidak membasahi baju yang dipakai oleh pasien. Hingga saat ini, di KRIPMD PKU Muhammadiyah Kutoarjo belum pernah dilakukan penelitian untuk melihat perbedaan efektivitas kompres pada daerah dahi dan aksila.

Tujuan penelitian ini adalah untuk mengetahui perbedaan efektivitas pemberian kompres air hangat di aksila dan dahi terhadap penurunan suhu tubuh pada pasien demam di KRIPMD PKU Muhammadiyah Kutoarjo.

\section{BAHAN DAN METODE}

Dalam penelitian ini, desain penelitian yang digunakan adalah penelitian true eksperimen: twogroup pre-post test design. Penelitian ini dilakukan di Klinik Rawat Inap Pelayanan Medik Dasar PKU Muhammadiyah Kutoarjo. Penelitian ini dilakukan pada bulan November 2013. Populasi pada penelitian ini adalah semua pasien yang dirawat di Ruang Rawat Inap KRIPMD PKU Muhammadiyah Kutoarjo yang mengalami demam dengan suhu tubuh aksila $\geq 38^{\circ} \mathrm{C}$ berjumlah 40 pasien dalam satu bulan. Variabel independen dalam penelitian ini adalah pemberian kompres hangat pada daerah dahi atau daerah aksila. Variabel dependen dalam penelitian ini adalah penurunan suhu tubuh pada pasien demam. Subjek dibagi dua kelompok, yaitu kelompok dengan kompres hangat pada dahi dan kompres hangat pada aksila selama 15-30 menit. Pengukuran dilakukan 2-3 menit sebelum perlakuan kompres dengan menggunakan thermometer aksila. Analisis data menggunakan uji $t$.

\section{HASIL DAN BAHASAN}

\section{Analisis Univariat}

\section{Karakteristik Responden}

Berdasarkan Tabel 1 diketahui bahwa demam terbanyak terjadi pada pasien berumur antara 21-30 tahun yaitu $28,9 \%$ (11 orang) dan paling sedikit terjadi 
pada pasien umur $31-40$ tahun yaitu 10,5\% (4 orang). Hasil tersebut kemungkinan karena subjek penelitian pada pasien demam terlalu sedikit yaitu hanya 38 orang dan jumlah responden yang berumur antara 21-30 tahun lebih banyak.

Tabel 1. Distribusi Frekuensi Umur Pasien Demam di KRIPMD PKU Muhammadiyah Kutoarjo

\begin{tabular}{ccc}
\hline Umur & $\mathbf{f}$ & $\mathbf{\%}$ \\
\hline 0-10 Tahun & 8 & 21,1 \\
11-20 Tahun & 5 & 13,2 \\
21-30 Tahun & 11 & 28,9 \\
31-40 Tahun & 4 & 10,5 \\
> 40 Tahun & 10 & 26,3 \\
Total & 38 & 100,0 \\
\hline
\end{tabular}

Sumber: Data Primer 2013

Hasil penelitian ini tidak sesuai dengan teori Asmadi yang disebutkan bahwa salah satu faktor perubahan suhu tubuh dipengaruhi oleh umur. Dalam teori tersebut dijelaskan bahwa suhu pada usia anak- anak sampai masa puber dan pada usia lanjut cenderung lebih labil dibandingkan dengan usia dewasa(7).

Tabel 2. Distribusi Frekuensi Pendidikan Pasien Demam di KRIPMD PKU Muhammadiyah Kutoarjo

\begin{tabular}{lcc}
\hline \multicolumn{1}{c}{ Pendidikan } & f & \% \\
\hline Belum Sekolah & 3 & 7,9 \\
SD & 13 & 34,2 \\
SMP & 7 & 18,4 \\
SMA & 8 & 21,1 \\
Perguruan Tinggi & 7 & 18,4 \\
$\quad$ Total & 38 & 100,0 \\
\hline
\end{tabular}

Sumber: Data Primer 2013

Berdasarkan Tabel 2 diketahui pendidikan pasien terbanyak adalah SD yaitu $34,2 \%$ (13 orang) sedangkan jumlah paling sedikit termasuk kategori belum sekolah yaitu 7,9\% (3 orang).

Berdasarkan Tabel 3 diketahui bahwa frekuensi terbanyak pasien demam adalah pelajar/mahasiswa yaitu $34,1 \%$ (13 orang) dan frekuensi paling sedikit adalah belum sekolah yaitu $7,9 \%$ (3 orang). Pelajar dan mahasiswa pada jaman sekarang sebagian memiliki pola makan yang tidak baik dengan pola gizi yang tidak seimbang sehingga lebih mudah terserang demam sebagai awal gejala penyakit yang terjadi. Penelitian Carolina menyebutkan bahwa pola makan yang tidak sehat menyebabkan seseorang lebih mudah terserang suatu penyakit(8).

Berdasarkan Tabel 4 diketahui bahwa pasien demam terbanyak berjenis kelamin perempuan yaitu
Tabel 3. Distribusi Frekuensi Pekerjaan Pasien Demam di KRIPMD PKU Muhammadiyah Kutoarjo

\begin{tabular}{lcc}
\hline \multicolumn{1}{c}{ Pekerjaan } & f & \% \\
\hline Buruh/Tani & 9 & 23,7 \\
IRT & 5 & 13,2 \\
Swasta & 8 & 21,1 \\
Pelajar/Mahasiswa & 13 & 34,1 \\
Belum Sekolah & 3 & 7,9 \\
$\quad$ Total & 38 & 100,0 \\
\hline
\end{tabular}

Sumber: Data Primer 2013

Tabel 4. Distribusi Frekuensi Jenis Kelamin Pasien Demam di KRIPMD PKU Muhammadiyah Kutoarjo

\begin{tabular}{lcc}
\hline \multicolumn{1}{c}{ Jenis Kelamin } & f & \% \\
\hline Laki-Laki & 18 & 47,4 \\
Perempuan & 20 & 52,6 \\
\multicolumn{1}{c}{ Total } & 38 & 100,0 \\
\hline
\end{tabular}

Sumber: Data Primer 2013

Tabel 5. Distribusi Frekuensi Riwayat Penyakit Pasien Demam di KRIPMD PKU Muhammadiyah Kutoarjo

\begin{tabular}{ccc}
\hline Riwayat Penyakit & f & $\%$ \\
\hline Demam Thypoid & 26 & 68,4 \\
Diare/ GE & 12 & 31,6 \\
Total & 38 & 100,0 \\
\hline
\end{tabular}

Sumber: Data Primer 2013

$52,6 \%$ (20 orang) dan jumlah paling sedikit adalah berjenis kelamin laki-laki yaitu $47,4 \%$ (18 orang). Hasil penelitian ini didukung oleh oleh Asmadi yang menyebutkan bahwa salah satu faktor yang mempengaruhi peningkatan suhu tubuh adalah hormon(3). Wanita mengalami peningkatan hormon lebih banyak daripada pria. Pada wanita terjadi peningkatan suhu antara $0,3-0,6^{\circ} \mathrm{C}$ di atas suhu basal saat terjadi sekresi progesteron pada saat ovulasi berlangsung(9).

Berdasarkan Tabel 5 diketahui bahwa pasien demam terbanyak memiliki riwayat penyakit demam thypoid yaitu $68,4 \%$ (26 orang) dan kejadian dengan frekuensi lebih sedikit terjadi pada pasien dengan riwayat penyakit diare/GE yaitu 31,6\% (12 orang).

\section{Derajat Penurunan Suhu}

Berdasarkan Tabel 6 diketahui bahwa rerata penurunan suhu tubuh pada pasien demam yang diberikan perlakuan kompres air hangat pada daerah aksila adalah $0,247^{\circ} \mathrm{C}$ dan rerata penurunan suhu tubuh pasien demam yang diberikan kompres air hangat pada daerah dahi adalah $0,111^{\circ} \mathrm{C}$. 
Tabel 6. Statistik Deskriptif Penurunan Suhu pada Pasien Demam yang diberikan Kompres Air Hangat pada Daerah Aksila dan Daerah Dahi di KRIPMD PKU Muhammadiyah Kutoarjo

\begin{tabular}{lcc}
\hline $\begin{array}{c}\text { Statistik } \\
\text { Deskriptif }\end{array}$ & $\begin{array}{c}\text { Kompres pada } \\
\text { daerah Aksila }\end{array}$ & $\begin{array}{c}\text { Kompres pada } \\
\text { daerah Dahi }\end{array}$ \\
\hline Mean & 0,247 & 0,111 \\
Deviation & 0,077 & 0,066 \\
Minimum & 0,100 & 0,000 \\
Maximum & 0,400 & 0,200 \\
\hline
\end{tabular}

Sumber: Data Primer 2013

\section{Analisis Bivariat}

Uji Beda Rerata Suhu Tubuh pada Pasien Demam Sebelum Perlakuan pada Pasien yang Dikompres pada Daerah Aksila dan Rerata Suhu pada Pasien yang Dikompres pada Daerah Dahi

Analisis data dilakukan dengan membandingkan rerata suhu tubuh sebelum perlakuan pada pasien yang diberikan kompres air hangat pada daerah aksila dan rerata suhu tubuh pada pasien demam yang diberikan kompres pada daerah dahi menggunakan independent sample $t$ test.

Tabel 7. Uji Beda Rerata Suhu Sebelum Perlakuan pada Pasien Demam yang dikompres pada Daerah

Aksila dengan Pasien Demam yang Dikompres pada Daerah Dahi di KRIPMD PKU Muhammadiyah Kutoarjo

\begin{tabular}{lccc}
\hline Lokasi Kompres & Rerata (Mean) & $\mathbf{t}_{\text {hitung }}$ & p-value \\
\hline Aksila & 39,02 & 1,984 & 0,055 \\
Dahi & 38,68 & & \\
\hline
\end{tabular}

Berdasarkan Tabel 7 diketahui rerata suhu tubuh pada pasien demam sebelum diberikan kompres pada daerah aksila adalah 39,02 dan rerata suhu tubuh sebelum pada daerah dahi sebesar 38,68 . Hasil uji beda diperoleh $t$ hitung sebesar 1,984 dengan $p=0,055$. Karena $p>0,05$ menunjukkan tidak ada perbedaan signifikan rerata suhu tubuh sebelum dilakukan perlakuan pada pasien demam yang dikompres pada daerah aksila dengan pasien yang dikompres pada daerah dahi.

Uji Beda Rerata Suhu Tubuh Sebelum dan Sesudah Perlakuan pada Pasien yang Dikompres pada Daerah Aksila dan Pasien yang Dikompres pada Daerah Dahi

Uji ini digunakan untuk membandingkan suhu sebelum dan sesudah perlakuan baik pada pasien demam yang dikompres dengan menggunakan air hangat pada daerah aksila maupun pasien demam yang diberikan kompres air hangat pada daerah dahi menunjukkan penurunan yang signifikan. Hasil menunjukkan penurunan suhu yang signifikan jika $p<0,05$.

Tabel 8. Uji Beda Rerata Suhu Badan sebelum dan sesudah Perlakuan terhadap Pasien yang Dikompres pada Daerah Aksila Dahi

\begin{tabular}{llllll}
\hline $\begin{array}{l}\text { Lokasi } \\
\text { Kompres }\end{array}$ & $\begin{array}{c}\text { Sebelum dan } \\
\text { Sesudah } \\
\text { Perlakuan }\end{array}$ & Deviasi & $\mathbf{t}_{\text {hitung }}$ & p-value \\
\hline Daerah & Sebelum 39,02 & 0,247 & 13,961 & 0,000 \\
Aksila & Sesudah 38,77 & & & \\
Daerah & Sebelum 38,68 & 0,111 & 7,234 & 0,000 \\
Dahi & Sesudah 38,57 & & & \\
\hline
\end{tabular}

Sumber: Data Primer 2013

Berdasarkan hasil uji diperoleh penurunan suhu pada kedua kelompok lokasi kompres yaitu menunjukkan hasil yang signifikan. Pada kelompok pasien yang dikompres pada daerah aksila rerata suhu sebelum perlakuan adalah $39,02^{\circ} \mathrm{C}$ dengan rerata penurunan suhu $0,247^{\circ} \mathrm{C}$ menjadi $38,77^{\circ} \mathrm{C}$.

Pada pasien yang dikompres pada daerah dahi rerata suhu tubuh sebelum perlakuan adalah $38,68^{\circ} \mathrm{C}$ mengalami penurunan sebesar 0,111 menjadi $38,57^{\circ} \mathrm{C}$ sesudah perlakuan. Berdasarkan perbandingan penurunan suhunya maka pengompresan di daerah aksila dengan rerata penurunan suhu sebesar $0,247^{\circ} \mathrm{C}$ menunjukkan penurunan suhu yang lebih besar dibandingkan pengompresan pada daerah dahi dengan rerata penurunan suhu sebesar $0,111^{\circ} \mathrm{C}$.

Uji Beda Rerata Penurunan Suhu Tubuh Pasien Demam yang Dikompres pada Daerah Aksila dan Pasien Demam yang Dikompres pada Daerah Dahi

Tabel 9. Uji Beda Rerata Penurunan Suhu Badan Pasien Demam yang Dikompres pada Daerah Aksila dan Pasien Demam yang Dikompres pada Daerah Dahi

\begin{tabular}{lccc}
\hline Lokasi Kompres & $\begin{array}{c}\text { Rerata Penurunan } \\
\text { suhu }\end{array}$ & $\mathbf{t}_{\text {hitung }}$ & p-value \\
\hline Daerah Aksila & 0,247 & 5,879 & 0,000 \\
Daerah Dahi & 0,111 & & \\
\hline
\end{tabular}

Berdasarkan Tabel 9 diketahui bahwa rerata penurunan suhu tubuh pada pasien demam yang dikompres pada daerah aksila adalah 0,247 dan rerata penurunan suhu tubuh pada pasien demam yang dikompres pada daerah dahi adalah 0,111. Setelah dilakukan uji perbandingan kedua rerata menggunakan uji $t$ diperoleh t hitung sebesar 5,879 dengan $p=0,000$. Karena $p<0,05$ maka Ho ditolak dan Ha diterima, artinya ada perbedaan secara signifikan pada rerata penurunan suhu pada pasien 
yang diberikan kompres air hangat pada daerah aksila dan pasien yang diberikan kompres air hangat pada daerah dahi. Hal ini menunjukkan bahwa teknik pemberian kompres air hangat pada daerah aksila lebih efektif terhadap penurunan suhu tubuh dibandingkan dengan teknik pemberian kompres air hangat pada daerah dahi pada pasien demam di Klinik Rawat Inap Pelayanan Medik Dasar PKU Muhammadiyah Kutoarjo.

Hasil penelitian ini juga sesuai dengan teori yang dikemukakan oleh Tamsuri yang menyatakan daerah ketiak terdapat vena besar yang memiliki kemampuan proses vasodilatasi yang sangat baik dalam menurunkan suhu tubuh dan sangat dekat dengan otak yang merupakan tempat terdapatnya sensor pengatur suhu tubuh yaitu hypothalamus(10). Hasil penelitian ini mendukung hasil penelitian Juwariyah bahwa kompres air hangat lebih efektif $74,6 \%$ untuk menurunkan suhu pada pasien anak dengan demam daripada kompres plester(11). Hasil penelitian didukung hasil penelitian Sukmawati yang menunjukkan kompres di ketiak memberikan efektivitas tinggi bila dibandingkan kompres di dahi dengan derajat penurunan suhu masing $0,234^{\circ} \mathrm{C}$ dan $0,145^{\circ} \mathrm{C}(12)$. Hasil analisis menggunakan uji $t$ diperoleh $t$ hitung sebesar 5,673 dengan $p=0,018$. Serta penelitian Wening menyatakan bahwa pasien yang dikompres di bagian ketiak memiliki penurunan suhu lebih besar daripada pasien yang dikompress pada daerah dahi(13).

\section{SIMPULAN DAN SARAN}

Berdasarkan hasil penelitian dan pembahasan yang telah dipaparkan, dapat disimpulkan sebagai berikut bahwa rerata derajat penurunan suhu tubuh sebelum dan sesudah dilakukan kompres hangat pada daerah aksila pada pasien demam di KRIPMD PKU Muhammadiyah Kutoarjo sebesar $0,247^{\circ} \mathrm{C}$, rerata derajat penurunan suhu tubuh sebelum dan sesudah dilakukan kompres hangat pada daerah dahi pada pasien demam di KRIPMD PKU Muhammadiyah Kutoarjo sebesar $0,111^{\circ} \mathrm{C}$. Teknik pemberian kompres hangat pada daerah aksila lebih efektif terhadap penurunan suhu tubuh dibandingkan dengan teknik pemberian kompres hangat pada dahi pada pasien demam di KRIPMD PKU Muhammadiyah Kutoarjo. Saran bagi pasien dan keluarga agar dapat meningkatkan cara kompres di daerah aksila karena lebih efektif.

\section{RUJUKAN}

1. Sherwood L. Fisiologi Manusia dari Sel ke Sistem. Jakarta: EGC; 2002.

2. Ganong WF. Fisiologi Kedokteran. Jakarta: EGC; 2002.

3. Asmadi. Konsep Dasar Keperawatan. Jakarta: EGC; 2008.

4. Hegner BR. Asisten Keperawatan Suatu Pendekatan Proses Keperawatan. Jakarta: EGC; 2003.

5. Crowin. Buku Saku Patofisiolog. Jakarta: EGC; 2002.

6. Sunardi. Kontrol Persyarafan Terhadap Suhu Tubuh. Jakarta: Fakultas IImu Keperawatan Universitas Indonesia; 2009.

7. Asmadi. Konsep dan Aplikasi Kebutuhan Dasar Klien. Jakarta: EGC; 2008.

8. Carolina A. Hubungan Pola Makan dengan Kejadian Penyakit GE pada Remaja di Puskesmas Rempoah. Purwokerto: Akper Muhammadiyah Purwokerto; 2011.

9. Effendy F, Makhfudli. Keperawatan Kesehatan Komunitas. Jakarta: Salemba Medika; 2009.

10. Tamsuri A. Tanda-tanda Vital: Suhu Tubuh. Jakarta: EGC; 2006.

11. Juwariyah. Efektivitas Penurunan Suhu Tubuh Menggunakan Kompres Hangat dan Kompres Plester pada Anak Demam [internet]. 2011 [cited 2013 Des 26]. Available from: http://repository. usu.id.

12. Sukmawati. Perbandingan Penurunan Suhu pada Pasien yang Dikompres Pada Daerah Ketiak dengan Kompres Pada Dahi di RSI Ibnu Shina Magelang. Surakarta: Fakultas Kesehatan UMM Surakarta; 2010.

13. Wening, Endang. Perbandingan Penurunan Suhu Pada Pasien yang Dikompres pada Daerah Ketiak dengan Kompres pada Dahi di Ruang Rawat Inap Kelas III RS Hasan Sadikin Bandung. Bandung: Akper Parahiyangan; 2011. 